\title{
LAS MEMORIAS DEL GOBERNADOR CIVIL ANTONIO GUEROLA (1853-1878)
}

92: 353.2.075.31

por

Federico Suárez

Universidad de Navarra

SUMARIO: I. INTRODUCCION.-II. EL GOBERNADOR ANTONIO GUEROLA. - III. LAS OBRAS DE GUEROLA. - IV. LAS MEMORIAS.

\section{INTRODUCCION}

Con el título de Memoria de mi administración en la Provincia de (...) como Gobernador de ella desde (...) hasta (...), Antonio Guerola y Peyrolón escribió veintiocho volúmenes que dejan constancia de su paso por los Gobiernos civiles de Zamora, Oviedo, Málaga, Cádiz, Sevilla, Granada, Barcelona y, por segunda vez, con un lapso de doce años desde que cesó en Barcelona, de nuevo Sevilla.

Sin duda, bien merece ser conocido este rico e importante conjunto de Memorias por el evidente interés que tiene tanto para los historiadores como para los administrativistas, pues ni es fácil para los primeros adquirir noticias del género que Guerola proporciona, ni es frecuente que los segundos se encuentren con una muestra tan valiosa de lo que era la Administración vivida en una época en la que, si es fácil conocer las leyes y reglamentos, resulta casi impo- 
sible saber la proyección que tales disposiciones tenían en la realidad.

\section{EL GOBERNADOR ANTONIO GUEROLA}

Antonio Guerola era natural de Valencia. Nació en 1817 y, como su hermano Pedro María (1), estudió Leyes en la Universidad de Valencia. Otro hermano, José, siguió el mismo camino, y en 1843 cursó la instancia correspondiente para optar al grado de Licenciado en Jurisprudencia, después de haber estudiado (desde 1834) tres años de Filosofía y siete de Leyes y haber obtenido el grado de Bachiller en Leyes en 1841.

En el archivo de la Universidad de Valencia sólo se conserva, de Antonio Guerola, el expediente del grado de Bachiller (2), pero no es posible saber todavía, por falta de datos, si, como su hermano José, prosiguió sus estudios de Leyes hasta licenciarse, o si hubo de interrumpirlos. Al principio de su Memoria... de Zamora escribe, a modo de resumen sobre su vida: "Después de una larga carrera de oficial de Gobierno político y Secretario en los de Valencia, Barcelona y Madrid, me hallaba en la primavera de 1853 de oficial $1 .^{\circ}$ del Ministerio de la Gobernación» (3). Pero la expresión «larga carrera» conviene por igual tanto si la comenzó en 1837 (Bachiller en Leyes) como si lo hizo en 1841, cuando pudiera ya haber hecho la licenciatura.

Tampoco es posible determinar cuánto duraron sus empleos en los Gobiernos civiles de Valencia, Barcelona y Madrid, ni cuándo y cómo pasó a la plantilla del Ministerio de la Gobernación. Según una anotación suya, estuvo de Secretario del Gobierno civil de Barcelona siendo Gobernador don Melchor Ordóñez, a quien consideró

(1) Pedro María Guerola hizo su matrícula para el grado de Bachiller en Leyes en junio de 1835 . Un año después se graduó Antonio.

(2) La solicitud para optar al grado está fechada el 8 de octubre de 1836; al día siguiente, el Rector (Francisco Villalba) señaló el 11 para el ejercicio secreto, previo depósito de los derechos, que ascendieron a 162 reales. El día indicado se realizó el ejercicio $\mathrm{y}$, «aprobado en la tentativa nemine discrepante», pasó al examen público previo pago de otros 146 reales y 18 maravedís, señalándose el día 12 para tomar puntos. Elegida una de las tres proposiciones que le salieron en suerte, verificó al día siguiente el ejercicio público con éxito: «Día 13 de octubre. Fue examinado por los señores Mateu Estruch, Rosell Pardo, Andreu, Cavero, Rodríguez Palanca. Aprobado nemine discrepante, conferido en el acto por Mateu.-Quilis» (Archivo de la Universidad de Valencia. Expedientes, leg. 30).

(3) Antonio Guerola: Memoria de mi administración en la Provincia de Zamora como Gobernador de ella desde 12 de agosto de 1853 hasta 17 de julio de 1854, página 7 . 
explícitamente como su protector y con quien mantuvo cordiales relaciones siempre. Tenía Guerola treinta y seis años cuando cesó en el Ministerio y fue propuesto para su primer Gobierno civil, y hasta cierto punto fue este nombramiento, tal como él mismo cuenta, más una salida airosa que un premio a actuaciones políticas (4).

Guerola no era, al menos en esta época, un político (5), y en realidad no lo fue nunca, al menos en el sentido usual de la palabra, por lo que consideró que salía perdiendo con el cambio: "La plaza de oficial $1 .^{\circ}$ del Ministerio era preferible a la de Gobernador de $4 .^{a}$ clase, y aun de 2. ${ }^{a}$ La primera era descansada; en la segunda no hay descanso. En el rincón del Ministerio puede uno abstraerse de la política candente. Un Gobernador está por precisión metido en ella. En la Secretaría, un oficial laborioso puede lucirse sin riesgo; un Gobernador modelo se desluce y se desacredita con la mejor intención. En el sueldo es casi igual: 32.000 reales en el Ministerio y 35.000 en el Gobierno" (6).

Cesó en el verano de 1854, cuando la Vicalvarada puso fin al gobierno de los moderados y devolvió el poder a los progresistas. Guerola salió de Zamora y regresó a su tierra natal. Dos años estuvo residiendo en Valencia, con la sola interrupción de una breve temporada en Madrid «con motivo del cólera». Los progresistas no le molestaron: «ni un insulto, ni una vejación, ni aun esas molestias legales de la cuota para la Milicia Nacional, etc. Cumplo un grato deber de justicia consignándolo asì» (7).

Al terminar los progresistas su corto período de mando, y al ocupar Ríos Rosas el Ministerio de Gobernación, Guerola fue nombra-

(4) Cuando Egaña se hizo cargo del Ministerio de la Gobernación procedio, según era usual, a cambios en el personal del Ministerio, sustituyendo a unos veinte empleados, entre los que estuvo Guerola. En carta de 10 de julio, Egaña le comunicó haber «procurado una justa compensación proponiéndole a $\mathrm{S}$. M. para el gobierno de la Provincia de Huelva». Pero siendo esta Provincia por aquel entonces «un campo de Agramante», y ofreciéndole la oportunidad de ir a Zamora, optó por esta última. Cfr. Memoria cit., 8 y 10.

(5) En el capítulo 142 de su Memoria... de Malaga (tomo X) escribió de sí mismo: "Mis convicciones, lo mismo que mis sentimientos, me llevaban a ser ecléctico en política. Yo simpatizaba con los absolutistas en los principios religiosos. que gracias a Dios conservo incólumes, y en la adhesión a la Monarquía. Aceptaba del partido moderado la templanza, el amor al orden, el sentimiento conservador de los principios sociales para oponerlo a la invasión de las doctrinas socialistas y revolucionarias. Finalmente, de los partidos progresistas tomaba como bueno el afán de progresar en la mejora moral y material de la sociedad, y las instituciones liberales hermanadas con el orden y la Monarquía, porque rechazo el despotismo en todo orden civil» (pág. 10).

(6) Memoria ... de Zamora, pág. 9.

(7) A. Guerola: Memoria de mi adininistración en la Provincia de Oviedo como Gobernador de ella desde 7 de septiembre de 1856 hasta 18 de noviembre de 1857, I, página 7. 
do Gobernador de Oviedo. Esta vez sí tuvo cierto interés. Aspiraba al Gobierno civil de Baleares, por lo pacífica y tranquila que era esta Provincia; mas si la vez anterior logró su propósito de evitar una Provincia difícil (Huelva) para ir a una fácil, esta vez sucedió lo contrario. El 6 de septiembre de 1856 llegó a Oviedo, y al día siguiente tomó posesión de su cargo.

Siete meses después, en abril de 1857, Guerola, en situación molesta tras unas elecciones, escribió a Pidal solicitando su traslado a otra Provincia, aunque inútilmente. Obtuvo dos meses de licencia el 16 de agosto para restablecer su salud, aunque en realidad no se trataba de la suya. En 10 de agosto había escrito a Pidal: «Hace dos meses que mi mujer empeoró de sus habituales dolores de cabeza, mostrándose síntomas y principios de enajenación mental». A toda costa quería Guerola sacarla de Asturias, con la esperanza de que otro clima y la variación pudiera restablecerla o, al menos, aliviarla. No pudo utilizar la licencia. El 7 de septiembre su mujer perdió la razón, y un hijo, gravemente enfermo, impedía todo conato de viaje. Al cabo, las condiciones familiares en que se encontraba pesaron en el Ministro para que la mujer de Guerola (que se repuso del ataque de enajenación) y su hijo pudieran encontrar en un lugar de más benigno clima mejor ocasión de reponerse (8). Con fecha 14 de noviembre de 1857, Guerola fue nombrado Gobernador civil de Málaga.

Los motivos por los que a los cuatro años deseaba un nuevo cambio fueron un tanto egoístas, según él mismo confiesa: "Yo quería salir de Málaga bien, para quedar en aptitud de volver allí como particular siempre que quisiera, y para añadir a mi modesta hoja de servicios la página notable de haber estado tanto tiempo mandando en Málaga y haber salido con algún lucimiento. Por eso quería adelantarme a las circunstancias y salir bien antes de que ellas me obligasen a salir mal por alguno de esos conflictos a que siempre está expuesto todo Gobernador» (9). Por supuesto, no lo solicitó,

(8) Ríos Rosas había sido Ministro de la Gobernación en el Gabinete presidido por Leopoldo O'Donnell (del 14 de julio al 22 de octubre de 1856); a este Gabinete sucedió un nuevo Gobierno presidido por Narváez, ocupando Gobernación Cándido Nocedal. Dimitido el Ministerio el 15 de octubre de 1857, formó nuevo Gobierno Francisco Armero, que designó para Gobernación a M. Bermúdez de Castro. Alejandro Mon ocupó el Ministerio de Hacienda, y fue quien apoyó a Guerola para que se le concediese el cambio que venía solicitando con tanto interés como insistencia, puesto que (en palabras del mismo Guerola) era «ministro universal de hecho para todos los negocios de Asturias".

(9) A. Guerola: Memoria de mi administración en la Provincia de Málaga como Gobernador de ella desde el 6 de diciembre de 1857 hasta 15 de febrero de 1863, X, 303. 
pero sí solía hablar de ello con sus más íntimos amigos. Alguno de ellos, oficiosamente, lo hizo llegar a oídos de Cánovas del Castillo, Subsecretario entonces de Gobernación (10), que en 1861, en agosto, le ofreció la posibilidad de ir a Granada.

No llegaron a realizarse por entonces sus esperanzas y hubo de seguir al frente de la Provincia. A fines de 1862 «se empezó a notar en las regiones de la alta política los primeros síntomas de sucesos graves que estaban llamados a ser la causa de mi salida definitiva de Málaga». Tales síntomas fueron las disensiones dentro del partido Unión Liberal, e incluso dentro del Gabinete. Ríos Rosas capitaneó una facción disidente dentro del partido. Era malagueño e influyente en Málaga. Por otra parte, el general Serrano, que era «una figura importante, pero de posición no definida claramente respecto al Ministerio", tenía en la Provincia de Málaga numerosos familiares y adictos políticos. Cánovas, también malagueño, comenzó a mostrarse frío y distanciado de O'Donnell; Posada Herrera dimitió, y Cánovas con él. O'Donnell sustituyó a Posada nombrando al marqués de la Vega de Armijo, que no era precisamente amigo de Cánovas, con lo que Guerola se convenció de que sus días en el Gobierno de Málaga estaban contados. Así fue. El 13 de febrero de 1853 un telegrama particular le anunciaba el nombramiento de nuevo Gobernador (Feliciano Ramírez de Arellano). Guerola dejó el mando de la Provincia el 15, cuando ya sabía, por carta firmada por Vega de Armijo, que quedaba cesante, aunque con la seguridad -según decía la carta- de que «su cesantía de Vd. durará poco tiempo».

Así fue, en efecto. El Gabinete O’Donnell cayó el 2 de marzo, siendo sustituido por otro presidido por el marqués de Miraflores, que tenía al frente del Ministerio de la Gobernación a Florencio Rodríguez Vahamonde. El 31 de marzo, Guerola era de nuevo Gobernador civil, esta vez de Cádiz. Nota curiosa: cuando en 1861 quería Guerola un cambio, Cánovas le había escrito: «La ida a Cádiz no le conviene a $\mathrm{Vd}$., porque en aquella provincia los gobernados están siempre divorciados de los gobernantes, y está hecha para destruir reputaciones de Gobernadores, de tal suerte que todavia no ha salido uno con lucimiento después de algún tiempo» (11). Apenas

(10) Dimitido el Gabinete Istúriz (que había sustituido al presidido por Armero el 14 de enero de 1858), y formado nuevo Gobierno por $L$. O'Donnell en junio del mismo año, fue nombrado Ministro de la Gobernación Posada Herrera. Cánovas fue Subsecretario con él, siendo relevado del cargo de Gobernador civil de Cádiz que estaba desempeñando.

(11) Carta de Cánovas a Guerola, de 17 de agosto de 1861, en Memoria... de Málaga, X, 307. 
estuvo dos meses al frente de la Provincia, si bien no llegó a cumplirse la tradición que Cánovas asignaba a Cádiz. Salió, trasladado al Gobierno civil de Sevilla, el 31 de mayo, inexplicablemente para él, y en vísperas de elecciones. El Ministro de Fomento, M. Moreno López, sevillano, le dijo haber pedido él su traslado. Pero -añade Guerola- «a mí me quedó alguna sospecha de que influyese algo don Francisco de los Ríos Rosas, que a pesar de ser yo amigo suyo, quizás no creyó que lo era bastante para sus fines electorales y quiso tener a un amigo íntimo, cual lo era Ahumada» (12).

En Sevilla estuvo cuatro meses y unos días, y ello en pleno período electoral. «Es muy frecuente que al terminar unas elecciones generales a Diputados a Cortes haya cambio de Gobernadores, porque su influencia y su posición suelen quedar muy quebrantadas por los esfuerzos que se hacen para hacer triunfar las candidaturas ministeriales. Yo no me creía en este caso al concluir las elecciones en la Provincia de Sevilla» (13). Tranquilo, pues, en este aspecto, Guerola pidió un permiso para arreglar asuntos personales en Valencia. Salió en octubre de 1863, y después, de regreso de Valencia, visitó en Madrid al Ministro de la Gobernación, que se mostró satisfecho de su gestión. A los pocos días el Subsecretario le insinuó si aceptaría el Gobierno de La Coruña. Al pedir aclaración al Ministro, éste le dijo un tanto vagamente que deseaba un buen Gobernador en su tierra, cosa que no convenció en absoluto a Guerola. Al fin, como consecuencia de una de esas combinaciones habituales en las que se mezclan influencias personales y políticas (Narváez, en este caso), Guerola hubo de aceptar Granada.

El 27 de noviembre de 1863 tomó posesión de su nuevo destino, en el que, como en Cádiz, apenas estuvo dos meses. «Fui a Granada descontento, pero una vez instalado allí, y empezado el estudio de la Provincia, me hallaba contento y sin deseos de salir». Sin embargo, a pesar de su amistad con Alejandro de Castro, Ministro de Ultramar (14), de quien dice: "era para mí una garantía de estabilidad», y no obstante no haber tenido disgusto ni incidente alguno, y de haber comenzado a agilizar las cuestiones pendientes («había grande atraso en casi todos los ramos»), se vio sorprendido por un tele-

(12) A. Guerola: Memoria de mi administración en la Provincia de Cádiz como Gobernador de ella desde 31 de marzo de 1863 hasta 31 de mayo de 1863, pág. 296.

(13) A. Guerola: Memoria de mi administración en la Provincia de Sevilla, como Gobernador de ella, desde 14 de junio hasta 24 de octubre de 1863, II, 403.

(14) El Gobierno presidido por Miraflores había cesado el 17 de enero de 1864. Le sustituý uno de Arrazola, en cuyo Ministerio de Ultramar estaba Alejandro de Castro, desempeñando el de Gobernación. 
grama del Ministro de la Gobernación (Antonio Benavides) con estas escuetas palabras: Venga Vd. inmediatamente.

«Como en la Provincia no ocurría nada que exigiese mi presencia en Madrid, pensé naturalmente que se trataba de mi traslación o cesantía». No fue cesantía, sino traslado. A su llegada se encontró con el nombramiento para el Gobierno civil de Barcelona, «y el señor Castro explicó esto de una manera tan honrosa para mí que no me dejó ni el derecho a quejarme» (15). Las razones fueron que, siendo el Gabinete moderado-histórico «antipático en Cataluña», se necesitaba en una Provincia ya difícil de por sí, y en tal momento, un Gobernador "veterano en la carrera, de confianza para el Estado, y que por sus antecedentes no inspirara repulsión a los catalanes". Fue tanta la urgencia que el nombramiento apareció en la Gaceta al tiempo que Guerola llegaba a Madrid, de donde partió para Barcelona sin volver siquiera a Granada a despedirse.

«Desde que contra mi voluntad fui a Barcelona, formé la idea de que mi permanencia en aquel mando sería corta, y esta idea, que tenía por origen las dificultades de aquel Gobierno, se arraigó más en mí cuando hube tomado conocimiento de la situación de la Provincia. Convencido, pues, de que mi mando sería de corta duración, sólo deseaba salir bien, porque salir del Gobierno de Barcelona bien es un título recomendable en nuestra carrera» (16).

Al poco de llegar Guerola a Barcelona hubo nuevo cambio de Ministerio. El presidido por Alejandro Mon inició su vida el 1 de marzo de 1864, aunque el brillante equipo que lo componía (Pacheco, Mayáns, Ulloa, López Ballesteros, Cánovas) no fue suficiente para una larga permanencia o una fructífera gestión. El 15 de septiembre hubo de ceder paso a otra combinación, esta vez presidida por Narváez. Guerola aprovechó la ocasión de estar Cánovas del Castillo al frente de Gobernación para intentar un traslado, de modo que el 2 de marzo, en una carta de felicitación, escribía: "Confiado en la bondadosa amistad de Vd., de que tantas pruebas tengo recibidas, me permito recordarle ahora mis deseos antiguos y constantes de dejar la pesada carga de Gobernador por otro destino análogo en Madrid, que no me acorte la vida como sucede y debe suceder a todo el que lleva once años de faja verde. Si en las combinaciones que ahora ten-

(15) A. Guerola: Memoria de mi administración al frente de la Provincia de Granada, como Gobernador de ella, desde 27 de noviembre de 1863 hasta 25 de enero de $1864,304$.

(16) A. Guerola: Memoria de mi administración en la Provincia de Barcelona, como Gobernador de ella, desde 5 de febrero hasta 14 de julio de 1864, III, 119. 
ga Vd. entre manos se acuerda Vd. de mí, será un nuevo y grande favor que yo tendré que agradecerle» (17).

Cánovas le recomendó paciencia, diciéndole que no dejaría de tenerle en cuenta. Pero cuando el Gobierno se presentó a las Cortes, un grupo de Diputados catalanes se acercó a Cánovas para pedirle que mantuviera a Guerola en Barcelona, por considerarlo «conveniente a la buena administración de la Provincia». A primeros de julio aprovechó Guerola un conjunto de circunstancias coincidentes (recrudecimiento de la cuestión fabril, manejos revolucionarios, el rumor insistente de que el antiguo Gobernador le iba a sustituir) para informar a Cánovas y renovar su deseo de un puesto en el Ministerio. La influencia del Ministro de Hacienda medió para la salida de Guerola, que no fue tan airosa como en las anteriores ocasiones. Después de narrar prolijamente y con gran copia de documentación ilustrativa su cese, añade: «Tal fue mi salida de Barcelona, suceso que influyó en mi carrera, pues no he vuelto a ser empleado desde entonces (escrito esto en 1866), porque no he querido volver a ser Gobernador». Casi treinta años más tarde, en 1894, escribía: "Al volver a leer esta Memoria después de treinta años, quiero consignar dos cosas (...). La segunda es que mi cesantía, que en 1864 el señor Cánovas me hizo confiar sería corta, duró doce años». Cierto que hubo el trastorno que, iniciado en 1868, se prolongó hasta diciembre de 1874. Cuando Cánovas de nuevo volvió a la cumbre, nuevamente hizo Gobernador a Guerola, «y posteriormente Director general».

Antes, sin embargo, el marqués de Loring, que había comprado el ferrocarril de Sevilla a Cádiz, le había ofrecido la dirección del mismo, que Guerola aceptó, con un sueldo de 50.000 reales. Durante 1874 y 1875 Guerola permaneció en este puesto, muy a su gusto, ya que el trabajo le agradaba y, en realidad, carecía de ambición política. La venta de una parte importante de las acciones del ferrocarril dejó el puesto de Guerola a merced del nuevo socio mayoritario, y Guerola comenzó a pensar, una vez más, en un empleo en Madrid. «Loring, siempre bueno para mí, gestionó con Cánovas para que me diera una Dirección General, pero esto ofrecía dificultad, y como en febrero quedó vacante el Gobierno de Sevilla, me propuso si quería aceptarlo» (18).

(17) Ibid., 120.

(18) Antonio Guerola: Memoria de mi administración en la Provincia de Sevilla, como Gobernador de ella por segunda vez, desde 1 de marzo de 1876 hasta 5 de agosto de $1878,1,48$. 
Con todo, y a pesar de los buenos amigos y el ambiente de cordialidad que encontró en Sevilla, el deseo de Guerola de un trabajo más reposado en una Dirección General se manifestaba con más intensidad a medida que transcurría el tiempo, y desde el verano de 1877 se agudizó. Tenía ya sesenta años, era el Gobernador más antiguo de España, y también el que más años había estado al frente de Gobiernos civiles. Buenos amigos de Madrid - Cánovas, Romero Robledo, Silvela, Loring, etc.- se interesaron por su caso. Al fin, en julio de 1878, recibió un telegrama que decía: Está acordado el nombramiento de Vd. para Director de Hacienda, y probablemente será para el ramo de Estancadas. "Inesperadamente me encontré con el nombramiento, no para Estancadas, sino para la Dirección General de Administración en el Ministerio de la Gobernación, por Real Decreto de 30 de julio de 1878» (19).

En la Dirección General de Administración Local permaneció poco tiempo, pues pasó a desempeñar la de Beneficencia y Sanidad. En 1879, el 12 de marzo, fue nombrado Subsecretario de Gobernación, cargo que desempeñó hasta octubre del mismo año. Fueron estos quince meses de muy intenso trabajo, tanto que no pudo escribir.

Cuando, al dejar la Subsecretaría de Gobernación, pasó al Consejo de Estado, otra vez encontró el tiempo y el reposo para seguir escribiendo: «Sólo, pues, ahora que estoy en el Consejo de Estado, destino mucho más descansado, puedo emprender esta Memoria, que cerrará las de mi carrera de Gobernador, pues no pienso volver a serlo» (20). Contaba entonces sesenta y tres años.

Vivió todavía unos veinte más. En 1898 conservaba íntegramente el gusto por escribir, así como la claridad de ideas necesarias para hacerlo. De esta fecha es la última de sus obras, Proyecto de Ley de dementes. La enfermedad mental de su mujer, que tan dolorosamente conllevó durante largo tiempo, le dio una experiencia que intentó recoger en su Proyecto, intentando quizás evitar a otros sufrimientos que él mismo había padecido.

\section{LAS OBRAS DE GUEROLA}

Es un caso bien notable el de este hombre, ocupado toda su vida en tareas administrativas, en ocupaciones difíciles y poco propicias

(19) A. Guerola, ibid., VIII, 246.

(20) A. Guerola, ibid., Advertencia. 
al ejercicio de la pluma, y que sin embargo parece acuciado de una poderosa necesidad de escribir.

No conocemos de él nada anterior a sus Memorias, y es ésta, por tanto, la primera de sus obras que debe ser mencionada. Constituyen una de las fuentes más valiosas para el conocimiento de una época, y además de modo muy directo, pues lo que muestra es la rica, compleja y variada vida de unas Provincias de caracteres muy distintos.

Fue Gobernador civil de Zamora, Oviedo, Málaga, Cádiz, Sevilla, Granada, Barcelona y, por segunda vez, Sevilla. Al terminar su gestión redactó, en todos los casos, una Memoria de su administración en la correspondiente Provincia, Memoria que varía en extensión, según los casos. En total constituyen veintiocho volúmenes manuscritos, con un total de alrededor de 10.500 páginas en cuarto, de letra pequeña, en ocasiones poco clara, por el apresuramiento con que Guerola había tenido que redactarlas. A veces incluye planos de las distintas plantas de los edificios donde radicaban los Gobiernos civiles que desempeñó, o de los jardines, o transcribe correspondencia con personajes políticos de relieve (Mon, Pidal, Cánovas, Romero Robledo, Vega Armijo, etc.), así como documentos de muy distinta especie, con frecuencia encargando de ello a un amanuense.

He aquí la relación de los manuscritos:

Zamora.-Un volumen de 436 páginas (12 de agosto de 1853 a 17 de julio de 1854).

Oviedo.-Dos volúmenes de 465 y 456 páginas (2 de septiembre de 1856 a 18 de noviembre de 1857).

Málaga.-Diez volúmenes de 400, 400, 387, 405, 410, 420, 408, 405, 342 y 400 páginas (6 de diciembre de 1857 a 15 de febrero de 1863).

Cádiz.-Un volumen de 318 páginas ( 31 de marzo a 31 de mayo de 1863).

Sevilla.-Dos volúmenes de 360 y 440 páginas (14 de junio a 24 de octubre de 1863).

Granada.-Un volumen de 338 páginas (27 de noviembre de 1863 a 25 de enero de 1864).

Barcelona.-Tres volúmenes de 345, 256 y 230 páginas (5 de febrero a 14 de julio de 1864).

Sevilla (segunda vez).-Ocho volúmenes de 370, 414, 390, 414, $410,270,340$ y 270 páginas (1 de marzo de 1875 a 5 de agosto de 1877). 
Al frente de la primera de las Memorias, la de Zamora, puso una Advertencia que muestra su intención: «Me propongo escribir una memoria de mi administración en la Provincia de Zamora, no como documento que aspire a los honores de la publicidad, sino como simple recuerdo mío. Por eso va con el desaliño y abandono de un papel reservado. Es simplemente reunir los apuntes dispersos en mi cartera de bolsillo. Tengan esto presente si alguna vez estos fragmentos, por circunstancias que no puedo prevenir, salen del rincón de mi escritorio.-Valencia, 7 de abril de 1855. Antonio Guerola».

Esta Advertencia suele repetirse al comienzo de cada Memoria, pero ampliada en algunas ocasiones, tal como figura al comienzo de la de Oviedo: "Igual advertencia tengo que hacer ahora, pero con más insistencia respecto al desaliño. Por recoger recuerdos que el tiempo podrá borrar, he tenido que escribir estos apuntes atropelladamente. Los principié en los últimos días de mi permanencia en Oviedo; los continué en alta mar, a bordo del vapor que me conducía a mi nuevo Gobierno de la Provincia de Málaga, y los concluyo en esta capital, donde me falta completamente la tranquilidad de espíritu por la situación política de la población y la muy dolorosa de mi familia.-Málaga, 12 de febrero de 1858. Antonio Guerola» (21).

Estas anotaciones son las que permiten fijar las fechas en que las distintas Memorias se compusieron. Así, en el volumen I de Málaga figura la anotación: Madrid, 9 de septiembre de 1864, y en el último volumen, al final de la nota 14, esta otra: Madrid, 25 de enero de 1867.

En el primero de Sevilla (p. 4): Madrid, 8 de marzo de 1866; en el de Granada: Madrid, 6 de julio de 1866; en el primero de Barcelona: Madrid, 21 de agosto de 1866, y en el III (p. 247) esta otra: Madrid, 16 de mayo de 1894. Al acabar de releer esta memoria al cabo de treinta años...

Pero es el volumen I de Sevilla (segunda vez) el que proporciona pormenores de interés acerca de cómo fueron redactándose las $\mathrm{Me}$ -

(21) Se refiere a algunas conspiraciones de tipo socialista, a la enfermedad de su hijo y a la enajenación mental de su mujer, a que se aludio antes. De la familia de Guerola se conocen pocos datos: su mujer, Carmen, era hija única de José Miguel Vergés y de María de la Concepción Trives. Esta murió hacia 1847, dejando heredera universal a su hija. La madre de Guerola se llamaba Antonia. El padre debió fallecer hacia 1857 o principios de 1858 , pues en mayo de este último año tuvo lugar la división de la herencia. Tales datos aparecen en una de las obras manuscritas de Guerola acerca de sus bienes, y han sido anotadas aquí no como fruto de un estudio detenido, sino como resultado de una rápida ojeada al manuscrito. Heredó también Guerola en 1875 de su hermana Mariana. Probablemente un estudio detenido del manuscrito citado proporcionará muchos más datos acerca de Guerola y su familia. 
morias. Dice, en la Advertencia: «Debo, además, advertir que, otras veces, esta clase de memorias las he escrito a raíz de los hechos, porque apenas tomaba posesión del Gobierno de una Provincia empezaba a ocuparme, en los pocos ratos de descanso, de escribir la Memoria del Gobierno anterior». No pudo hacerlo así esta última vez por el excesivo trabajo que tuvo en las Direcciones Generales de Administración Local y Beneficencia y Sanidad, y en la Subsecretaría del Ministerio de la Gobernación. «Sólo, pues, ahora que estoy en el Consejo de Estado... puedo emprender esta Memoria, que cerrará las de mi carrera de Gobernador, pues no pienso volver a serlo. Tengo, pues, la desventaja de que los hechos son ya lejanos... Madrid, 7 de mayo de 1880 ». El volumen VIII de esta segunda Memoria de Sevilla se cierra con esta fecha: Madrid, 15 de mayo de 1881. Cuando se transcriban y estudien los distintos volúmenes es fácil que aparezcan otras indicaciones análogas, y se pueda llegar a establecer con toda precisión la fecha de redacción de todos y cada uno de los tomos.

En 1868, cuando llevaba cuatro años cesante de todo cargo público, se publicaron en Madrid los primeros volúmenes de una ambiciosa obra sobre la Administración pública, acerca de cuya redacción carecemos de datos. En el primer volumen se ocupaba Guerola de la Sanidad; en el segundo, del Orden Público, y en el tercero, de Establecimientos Penales. Según la Advertencia de los editores, el plan era ambicioso, pues bajo el título general de Estudios de Administración práctica deberían comprenderse doce volúmenes, cada uno de los cuales constituiría un tratado monográfico sobre una parcela de la Administración, pero (y esto es importante) desde un punto de vista práctico. Así lo expresó Guerola en el prólogo que precedía al primer tratado: "Veinticinco años de carrera administrativa, doce de ellos al frente de las principales Provincias de España, me han dado, a falta de ciencia que sólo Dios otorga, un poco de la experiencia que los hombres proporcionan».

El resto de los tratados que debían seguir a los tres que se publicaron, según el plan previsto, eran los siguientes:

IV. Instrucción pública.

V. Agricultura, Industria y Comercio.

VI. Opinión pública.

VII. Hacienda.

VIII. Quintas (en cuanto impuesto personal). 
IX. Administración provincial y municipal.

X. Funcionarios públicos y Administración contenciosa.

XI. Asuntos varios (estadística, división territorial, correos, telégrafos, alojamientos, suministros, etc.).

XII. Derechos políticos.

Hasta 1891 (desde 1868, y aparte las Memorias de su segundo mandato en Sevilla) no parece que escribiera nada, excepto artículos de periódico. De esta fecha es el manuscrito Memoria sobre el Monte de Piedad y la Caja de Ahorros de Madrid, escrita con ocasión de un concurso y bajo el lema "Gloria a Piquer», de algo más de cien páginas de letra menuda y cuidada.

$\mathrm{El}$ año siguiente escribió la Memoria sobre los vicios y abusos de la Administración local en España y sus remedios, que se conserva también manuscrito. También tiene un lema: «Más administración y menos política». Son 197 páginas en cuarto.

Ya antes quedó mencionado su Proyecto de Ley sobre dementes (1898), que debió revisar algún tiempo después, ya que una nota dice: Este proyecto está rectificado posteriormente por mí. Antonio Guerola. La letra de esta anotación es clara y firme, a pesar de los ochenta y un años que ya contaba entonces.

En un volumen aparte, también manuscrito, recogió el texto de algunos de sus discursos, bajo el epígrafe Discursos pronunciados por don Antonio Guerola y Peyrolón. Es un volumen en octavo y recoge quince discursos pronunciados entre 1860 y 1877 . No es posible saber aún si estos discursos los recoge también en sus Memorias de gobierno.

Por último, debe mencionarse otro manuscrito que él tituló $M e$. moria historial de fincas de Antonio Guerola. Es una detallada relación de sus bienes, especialmente de las fincas que poseía en Valencia, Játiva, Callosa del Segura, Mislata, Carcagente, Alcira. Tras la descripción de la finca, añade el título de posesión (herencia, adquisición), remontándose a sus anteriores poseedores, haciendo la historia de cada finca hasta donde le era conocida por los documentos, y adjuntando el plano (hecho a mano por él) de cada una.

Para completar este apartado deben citarse los artículos que publicó en La Voz de la Caridad, generalmente bajo el seudónimo de Fausto. Son tres tomos numerados (pero encuadernados juntos los dos primeros), sobre materias relacionadas con establecimientos pe- 
nales y sobre caridad y beneficencia (22). En una nota aclaró Guerola (tomo II) la razón de no firmar con su nombre: «En este tomo ya casi todos los artículos los firmaba con mi seudónimo Fausto, porque siendo en aquella época Gobernador de Sevilla, y luego Director general de Beneficencia y Subsecretario del Ministerio, quería evitar la crítica a que se prestaba el que funcionario tan ocupado tuviera tiempo para escribir artículos de periódico».

Por lo que respecta a su obra escrita, esto es todo cuanto hoy se conoce, y no es poco. Once o doce mil páginas es una copiosa producción, y cuando el contenido de esas páginas es rico en datos históricos y administrativos, como en este caso, entonces es, sin duda, una obra que merece ser conocida tanto por su significación como por el conocimiento que proporciona de una época peor conocida de lo que nos figuramos.

\section{LAS MEMORIAS}

En cuanto se ojean los índices de los veintiocho volúmenes de las Memorias de Guerola, lo primero que se advierte es su carácter fundamentalmente administrativo y la abundancia de datos de carácter económico y social. Las noticias de carácter directamente histórico-político, aun abundando, son escasas en comparación con el resto.

Lo segundo que se observa es que Guerola tenía un plan general para disponer el material con que contaba, algo así como un esquema de los aspectos que abarcaba el gobierno civil de una Provincia. Este esquema general sufría las reducciones o ampliaciones necesarias según el tiempo que permanecía al frente de la Provincia, ya que una estancia dilatada le permitía puntualizar más ciertos aspectos, o incluir otros que un paso breve por un Gobierno civil no daba tiempo a conocer.

Por otra parte, y de la misma manera que él mismo observó con

(22) El tomo II está encuadernado con el primero, formando ambos el volumen I. La portada del I dice: "Estudios penales.-Artículos publicados por don Antonio Guerola en la Revista titulada $L a V o z$ de la Caridad. Años 1870, 71, 72, 73 y 74.-Los artículos de Fausto son pseudónimo del mismo Guerola». La del tomo II: "Estudios penales.-Artículos publicados por don Antonio Guerola en la Revista titulada $\mathrm{La} \mathrm{Voz}$ de la Caridad, años $1875,76,77,78,79,80,81,82,83,84$. Tomo II.-Nota: Fausto es pseudónimo del mismo Guerola». El tomo III: «Artículos de don Antonio Guerola (o de su pseudónimo Fausto) sobre caridad y asuntos relacionados con ella, publicados en la Revista titulada $\mathrm{La} \mathrm{Voz}$ de la Caridad». Con gran frecuencia aparecen, junto a los artículos de Guerola, los de Concepción Arenal, asidua colaboradora de la citada revista. 
relación a los Estudios de Administración práctica, sus Memorias de gobierno no son un pretexto para teorizar, aunque no dejara de hacer de vez en cuando algunas observaciones si venían a propósito. Fundamentalmente muestran la administración vivida. Acaso sea éste el mejor -y el mayor- de los valores que tienen estas Memorias: muestran la vida de una Provincia tal cual realmente se desarrollaba en el periodo central del siglo xIx: la miseria y la incipiente industria, las comunicaciones y el trabajo de los empleados públicos, las diversiones y la instrucción, el orden público y las contribuciones, los conflictos de trabajo y las revoluciones, la repercusión en las Provincias de problemas generales y los caracteres locales, la salud y la beneficencia, el contrabando y las Cajas de Ahorro o los Bancos agrícolas, las minas y los montes, los proyectos y las realizaciones, los obstáculos y los esfuerzos por vencerlos, las elecciones y las banderías políticas.

Algunos epígrafes se repiten constantemente, y casi siempre en el mismo lugar, en todas las Memorias. Entre ellos deben mencionarse, en primer término, los que suele titular «Mi nombramiento y llegada» y "Salida mía de...» la Provincia correspondiente. Tienen interés porque en ellos, aparte los datos útiles para la biografía de Guerola, suelen encontrarse noticias de carácter político, así como correspondencia cruzada entre Guerola y los personajes públicos de turno.

Invariablemente también da en todas ellas una "Descripción de la Provincia", interesante por muchos conceptos, ya que, aunque a veces con brevedad, toca aspectos tales como extensión, población, villas o pueblos con mayor número de vecinos, geografía, productos agrícolas más importantes, el clima, industria y comercio, riqueza forestal y minera, carácter de los habitantes. Y como complemento de esta descripción, la situación política: situación de los partidos políticos en la Provincia, personajes influyentes en la capital o los pueblos y sus tendencias, condiciones sociales, etc.

Otro capítulo, fijo también en todos los casos, es el referente a «Personal de autoridades y funcionarios públicos» (23). En alguna ocasión, al tratar de la «Secretaría del Gobierno de Provincia» (epígrafe que incluye en casi todas las Memorias), traslada el reglamen-

(23) Bajo el epígrafe "Personal de autoridades y funcionarios públicos», o simplemente «Personal de funcionarios públicos», suele dar una relación de todos ellos, siguiendo por lo general la pauta que le venía dada por las oficinas o delegaciones que los distintos ramos de la Administración tenía en la Provincia, llegando incluso al personal de las Casas de Socorro, Hospital o Correos y Telégrafos. 
to que él mismo compuso para poner un poco de orden en el desarreglo que observó en el trabajo de los funcionarios a su llegada al Gobierno civil.

No dedica un epígrafe expreso a obras públicas, pero se ocupa invariablemente de ellas en distintos apartados y de un modo $u$ otro en todas las Memorias. En la de Zamora, por ejemplo, dedica sendos epígrafes al canal de Valderaduey, navegación del Duero, ferrocarril del Norte, y caminos; en la de Oviedo trata separadamente de obras públicas, ferrocarril, puertos y caminos vecinales; en la de Málaga dedica casi un volumen entero a esta materia.

Desde el punto de vista político es de gran interés todo lo que se refiere a elecciones de Diputados de Cortes, que en ocasiones trata con gran detenimiento (por ejemplo, todo el volumen II de la Memoria de su gobierno en Sevilla la primera vez, con 400 páginas). Los sucesos de Loja y el viaje de la Reina a Málaga, conspiraciones revolucionarias, el motín de Marchena, la Reina Mercedes y la estancia de Alfonso XII en Sevilla, etc., tienen interés histórico y aportan datos valiosos en este punto, así como los datos sobre personajes políticos y su correspondencia con ellos.

En casi todas las Memorias recoge aspectos que muy difícilmente pueden averiguarse por otro conducto. Así, en su Memoria de Oviedo, cuando habla de la "emigración a América», o de las "concesiones a los segadores", en la de Málaga; o lo referente a imprentas y periódicos, que trata en casi todas las Memorias, así como teatros o juegos prohibidos; o de las sociedades mercantiles, crisis fabril y crisis metálica, y la fundación de los coros Clavé, en la $M e$ moria de Barcelona; guerra de Africa, etc.

$Y$ es de agradecer que Guerola llevara su cuidadosa pulcritud al escribirlas a incluir al fin de todos los volúmenes unas notas (algunas muy valiosas para determinar su valor como fuente histórica), y en la Memoria de Málaga un "Repertorio de las personas citadas en este tomo» en cada uno de los diez de que consta, así como un índice de cada uno de los veintiocho volúmenes que escribió de su gestión como Gobernador civil.

Ahora bien: es notorio (por lo que a historia se refiere, no a la Administración) que nuestro conocimiento del reinado de Isabel II, en el que transcurrió casi toda la actividad de Guerola como Gobernador civil (tan sólo su segunda gestión en Sevilla tuvo lugar durante la Restauración), está limitado casi exclusivamente a lo que la historiografía nos ha querido mostrar. La documentación que per- 
mite trabajos monográficos es poco conocida, y por ello esta clase de estudios sobre temas de esta época es escaso. El gran valor de las Memorias de Guerola es, a mi juicio, la ingente cantidad de datos concretos y seguros que sobre aspectos tan varios, como varia es la vida real, aporta para el conocimiento de esta época.

Con relación al valor de los datos que Guerola proporciona en las Memorias hay que afirmar en principio la absoluta solvencia del autor. Desde luego, es ya una recomendación a su favor el tono mesurado que, desde principio al fin y a lo largo de diez mil páginas, adopta, sin excesos verbales ni maledicencia, ni tampoco ensañamiento al tratar de personas que de un modo u otro le perjudicaron. El respeto con que trata a cuantos aparecen en su relación, incluso a aquellos con quienes acaso pudiera haberse permitido alguna acritud, es general. Pero no es esta la única, ni tampoco la principal razón por la que el valor de estas Memorias, en cuanto a credibilidad y confiado uso de sus datos, es alto y muy superior a otras.

Cuando nombraron a Guerola Gobernador de Málaga, Melchor Ordóñez, de quien había sido Secretario en el Gobierno Civil de Barcelona, escribió a sus numerosas amistades de aquella ciudad recomendando a su protegido, de quien dijo ser «incapaz de doblegarse a exigencia de persona alguna, enemigo de dejarse dominar por camarillas, tan poco dado a la política como entusiasta de las mejoras materiales» (24). Su talante de hombre honrado que procuraba cumplir su deber, su carencia de ambición política (aunque tuviera la legítima ambición de progresar en su carrera de funcionario), su instintiva repugnancia a maniobras poco conformes con su conciencia y su concepto del honor, así como el carácter reservado de las Memorias, "simple recuerdo mío", reunión de "apuntes dispersos» destinados a un "rincón de mi escritorio», es ya una garantía. Hay, además, algunos testimonios objetivos que refuerzan esta impresión de veracidad.

El primero de ellos, la abundancia de documentación. Muy frecuentemente transcribe oficios, informes y cartas, de modo que más que hacer una narración se limita a dejar hablar a los documentos,

(24) Cfr. Memoria... de Málaga, I, nota 3, en la que transcribe la carta de Ordóñez, fechada el 26 de noviembre de 1857 (Guerola fue nombrado el 6 de octubre anterior). Era Guerola enemigo de camarillas, pero no insociable. En Sevilla tuvo gran amistad con Fernán Caballero, «la mejor y más moral de las novelistas españolas», de la que tenía gran concepto: "no se mezcla nada en política, aunque su elevado talento la podía convertir en una Madame Stäel». La relación entre ambas familias debió ser grande, hasta el extremo de que en ausencia de los suyos, Guerola solía acudir habitualmente a las tertulias de Fernán Caballero: «todo allí era decoroso, ilustrado y simpático" (vid. Memoria... de Sevilla, I, cap. 2). 
sin pretender elaborar una imagen de los acontecimientos. Esto se percibe muy claramente en el tomo VIII de su Memoria de Málaga, al tratar de los sucesos de Loja. Es en el tomo X de esta misma $M e$ moria donde hallamos otro testimonio que abona en favor de la credibilidad de Guerola. Escribió al comenzar el capítulo sobre «Consideraciones generales sobre política» las siguientes palabras, que denotan, además, algunas de las dificultades que debió encontrar al redactarlas: "Tengo a la vista un voluminoso legajo, todo de política, donde está cuanto ocurrió en mi tiempo relacionado con ella, y no sé cómo ordenarlo para estas Memorias, porque hay muchas cosas que no puedo decir ni aun bajo el carácter confidencial que tienen estas Memorias. Por otra parte, grandes cuestiones, especialmente de política lugareña, que entonces me dieron mucho quehacer, quedaron luego sin importancia ni consecuencia, y me es hoy enojoso referirlas».

Hasta qué punto fue escrupuloso Guerola respecto a la exactitud de sus afirmaciones lo muestra este otro texto: «Bueno será consignar que lo que en esta Memoria se refiere procede, en la parte de documentos, de las copias de ellos que he conservado para este objeto, o de originales que obran en mi poder; y en la parte del texto, de mi memoria. Pero téngase presente que la memoria es flaca, y que algunos de los sucesos que relato tienen ya encima el transcurso de siete $u$ ocho años, por lo cual pudiera suceder que en detalles, no en la esencia, cometiera involuntariamente algún error» (25).

Si algún día estas Memorias logran verse publicadas, no sólo historiadores y administrativistas encontrarán un material rico y bien ordenado, sino que también los interesados en temas sociales y económicos podrán disponer de un cuadro vivo y de datos reales y concretos de inestimable utilidad (26).

(25) Cfr. Memoria ... de Málaga, I, nota 1.

(26) Con el fin de dar una idea clara del contenido de las Memorias, transcribimos a continuación el índice de la de Cádiz: «1. Descripción de la Provincia de Cádiz.-2. Condiciones políticas y sociales de la Provincia.-3. Personal de funcionarios públicos.-4. Mi nombramiento y llegada a Cádiz.-5. Secretaría del Gobierno.-6. Relaciones con las autoridades y principales funcionarios y gobernaciones.-7. Administración de los fondos provinciales.-8. Correos.-9. Habitación del Gobernador.10. Caminos.-11. Instrucción pública.-12. Beneficencia.-13. Patronatos.-14. Presidio.-15. Cárceles.-16. Reemplazo del ejército.-17. Hacienda.-18. Vigilancia.19. Contabilidad municipal.-20. Pósitos.-21. Visitas a la Provincia._22. Inauguración de las obras del faro de Chipiona.-23. Puertos.-24. Incendio de la aldea de Barbate.-25. Langosta.-26. Estadística.-27. Juegos prohibidos.-28. Teatros.-29. Periódicos.-30. Aprovechamiento de aguas.-31. Salida mía de Cádiz.-Notas». 